\title{
P367: Airborne decontamination system in hospital background
}

\author{
S Loeffert ${ }^{*}$, A Hautemaniere \\ From 2nd International Conference on Prevention and Infection Control (ICPIC 2013) \\ Geneva, Switzerland. 25-28 June 2013
}

\section{Introduction}

Since the commercial use of Formalin chemicals, classified as carcinogenic, has been forbidden, Airborne Decontamination Systems (ADS) have been revalued by the use of new disinfection products and technology.

\section{Objectives}

The aim of this review was to review all ADS of environmental surfaces which have been tested until today to control the spread of hospital-acquired pathogens and infections.

\section{Methods}

Research were conducted online using PubMed. All reports with experimental study about the impact of ADS on nosocomial pathogens were included. The main key words used for this selection were: air disinfection \& hydrogen peroxide, aerosol \& disinfection \& efficacy, aerosol \& hydrogen peroxide vapour. The selected papers included in the review were those in which we could calculate the logarithm reduction due to ADS. A comparison was made according to the products used, the different systems applied and the efficacy found.

\section{Results}

In the end, 21 papers consisting of 28 ADS experiments were included in this review. A large variety of products used for ADS are presented i.e.: hydrogen peroxide $\left(\mathrm{H}_{2} \mathrm{O}_{2}\right)$, ozone $\left(\mathrm{O}_{3}\right)$, metastable hypochlorus acid ( $\left.\mathrm{HA}\right)$, solution of bioflavanoids \& fruit acids extracts (Citrox), triethylene glycol (TEG) and gas plasma. 18 papers have studied ADS using $\mathrm{H}_{2} \mathrm{O}_{2}$ with a range of concentration from $12 \mathrm{ppm}$ to $700 \mathrm{ppm}$. Three papers used ADS with a range of $\mathrm{O}_{3}$ going from $0.04 \mathrm{ppm}$ to $25 \mathrm{ppm}$. One paper presented ADS using a concentration of about
2 ppm of TEG. Another study compared ADS system with $1000 \mathrm{ppm}$ of metastable HA and ADS with a 5\% Citrox solution. A part of human pathogens frequently found in hospitals and more precisely in patient surroundings were exposed to this variety of ADS. According to each study, location, exposure time and concentration of inoculums differ. In a general way, after ADS exposition the logarithm reduction observed is comprised between $0.33-\log _{10}$ and over $7-\log _{10}$. The ADS which seems to be the most effective against a large range of germs is the $\mathrm{H}_{2} \mathrm{O}_{2}$ vapor systems with a logarithm reduction ranged from $<0.6-\log _{10}$ to $>7-\log _{10}$.

\section{Conclusion}

Despite all the new technology and products created for ADS and the lack of international standard, this review suggests that their efficacy is depending on the products used, the experimental conditions applied and the germs tested.

\section{Disclosure of interest}

None declared.

Published: 20 June 2013

doi:10.1186/2047-2994-2-S1-P367

Cite this article as: Loeffert and Hautemaniere: P367: Airborne

decontamination system in hospital background. Antimicrobial Resistance and Infection Control 2013 2(Suppl 1):P367.

Meurthe et Moselle, University of Lorraine, Nancy, France

(0) 2013 Loeffert and Hautemaniere; licensee BioMed Central Ltd. This is an Open Access article distributed under the terms of the BFoMed Central Creative Commons Attribution License (http://creativecommons.org/licenses/by/2.0), which permits unrestricted use, distribution, and reproduction in any medium, provided the original work is properly cited. 